\title{
Anesthetic experience of methemoglobinemia detected during general anesthesia for gastrectomy of advanced gastric cancer -A case report-
}

\author{
Sam Soon Cho, Yong Duck Park, Jae Hoon Noh, Kyoung Oh Kang, Hee Jung Jun, and Jin Sun Yoon \\ Department of Anesthesiology, Seoul Veterans Hospital, Seoul, Korea
}

Methemoglobinemia is an uncommon but potentially fatal disorder. Most cases have no adverse clinical consequence and require no treatment, but methemoglobinemia is often overlooked as a cause of low oxygen saturation, and often mistaken for the more common causes of hypoxia by anesthesiologists despite simple bedside tests that indicate the presence of this treatable abnormality. We present a 68-year-old female patient who underwent gastrectomy for advanced gastric cancer with bleeding. In the preoperative period, the patient showed cyanosis and oxygen saturation was $85 \%$ by pulse oximeter, but oxygen saturation by arterial blood gas analysis was $100 \%$. After tracheal intubation, the methemoglobin level was $18.3 \%$. Ascorbic acid and methylene blue were administered. During preanesthetic evaluation, the patient had not informed the anesthesiologist that she had been taking dapsone. (Korean J Anesthesiol 2010; 59: 340-343)

Key Words: Dapsone, Methemoglobinemia, Oximetry.

Methemoglobinemia is a hemoglobinopathy caused by high levels of methemoglobin that result from oxidation of ferrrous $\left(\mathrm{Fe}^{2+}\right)$ to the ferric state $\left(\mathrm{Fe}^{3+}\right)$ in hemoglogin. Methemoglobin cannot carry oxygen, leading to tissue hypoxia. Surgical patients rarely have methemoglobinemia, and most cases are mild and require no treatment. However, perioperative methemoglobinemia is often overlooked as a cause of low oxygen saturation, and is often mistaken for other pulmonary disorders such as atelectasis, pulmonary edema, pulmonary thromboembolism, or inadequate anesthetic care such as esophageal intubation. We report our experience of a dapsoneinduced methemoglobinemia detected during general anesthesia of a 68-year-old female patient who underwent gastrectomy for advanced gastric cancer with hemorrhage and perforation.

\section{Case Report}

A 68-year-old female patient with advanced gastric cancer presented for a gastrectomy. She was under drug treatment for

Received: April 30, 2009. Revised: 1st, June 2, 2009; 2nd, June 24, 2009. Accepted: July 29, 2009.

Corresponding author: Sam Soon Cho, M.D., Department of Anesthesiology, Seoul Veterans Hospital, Dunchon-dong, Gangdong-gu, Seoul 134-060, Korea. Tel: 82-2-2225-1756, Fax: 82-2-2225-1416, E-mail: samsoon0308@hanmail.net

(c) This is an open-access article distributed under the terms of the Creative Commons Attribution Non-Commercial License (http:// creativecommons.org/licenses/by-nc/3.0/), which permits unrestricted non-commercial use, distribution, and reproduction in any medium, provided the original work is properly cited. 
diabetes and hypertension. Preoperative complete blood count showed hemoglobin at $8.9 \mathrm{~g} / \mathrm{dl}$ and hematocrit at $26.5 \%$. Arterial blood gas analysis was not performed. The electrocardiography, chest $\mathrm{x}$-ray, and pulmonary function test showed no abnormal findings.

After arriving at the OR, the patient monitoring system (Polymount Philips, USA) was used to monitor the blood pressure, heart rate, pulse rate, and oxygen saturation by pulse oximeter. She appeared stable, with a heart rate of $85 \mathrm{bpm}$, blood pressure 134/80 $\mathrm{mmHg}$, and respiratory rate $14 \mathrm{bpm}$, but oxygen saturation by pulse oximeter was $85 \%$ on both fingers but normal on the anesthesiologist's finger. Oxygen $6 \mathrm{~L} / \mathrm{min}$ was administered by mask, and no abnormal breathing sounds were detected. In arterial blood gas analysis, oxygen partial pressure was $307 \mathrm{mmHg}$ and oxygen saturation 100\% (Table 1). However, the conjunctiva were pale; her lips and fingernails were cyanosed; and the oxygen saturation by pulse oximeter did not rise above $90 \%$. The patient's guardian indicated that she had a 10-year history of grayish lips and fingernails. Although we considered delaying the surgery, the guardian wanted the surgery to proceed and the patient had the advanced gastric cancer accompanied by hemorrhage and perforation.

Before the anesthesia, a $20 \mathrm{G}$ catheter was placed in the radial artery for continuous hemodynamic monitoring and arterial blood gas analysis. After preoxygenation with oxygen at $6 \mathrm{~L} /$ min, lidocaine $20 \mathrm{mg}$, propofol $120 \mathrm{mg}$, and vecuronium 10 mg were administered, and manual ventilation was performed with oxygen at $6 \mathrm{~L} / \mathrm{min}$. However, the patient experienced severe cyanosis, and the oxygen saturation by pulse oximeter decreased to $79 \%$. After the tracheal intubation and controlled ventilation with oxygen at $3 \mathrm{~L} / \mathrm{min}$, the pulse oximeter increased to $83-85 \%$. In arterial blood gas analysis after induction, the sampled blood was dark blackish brown, oxygen partial pressure was $224.7 \mathrm{mmHg}$, and oxygen saturation was $96.6 \%$ (Table 1). The difference between oxygen saturation by arterial blood gas analysis and oxygen saturation by pulse oximeter was presumably due to dyshemoglobin. For confirmation, arterial blood gas analysis and hemoglobin analysis using a COoximeter (ABL520, Radiometer, Cofenhagen, Denmark) was ordered for the department of laboratory medicine. Arterial blood gas analysis showed normal findings and hemoglobin analysis showed methemoglobin at $18.3 \%$ and oxyhemoglobin at $81.5 \%$. Methemoglobinemia had caused cyanosis and low oxygen saturation by pulse oximeter. Ascorbic acid $600 \mathrm{mg}$ mixed in fluid was administered, and methylene blue $1 \mathrm{mg} /$ kg was intravenously injected slowly over 3 minutes. The methemoglobin level reduced to $11.2 \%$ after the administration of ascorbic acid and reduced to $4.3 \%$ and then $2.3 \%$ after methylene administration. Anesthesia was sustained with oxygen at $3 \mathrm{~L} / \mathrm{min}$ and enflurane $1.5-2.0$ vol\%. The surgery lasted 5 hours. The intraoperative oxygen saturation by pulse oximeter was $86-93 \%$. Blood pressure and pulse rate were stable. Two U of packed red blood cells were transfused. After the surgery, the patient had a normal recovery of consciousness and spontaneous respiration, but was transferred to the intensive care unit (ICU). In the ICU, oxygen $6 \mathrm{~L} / \mathrm{min}$ was administered by a Venturi mask. The oxygen saturation by pulse oximeter was $94 \%$. One day after the surgery, we found that the patient had taken daspone $100 \mathrm{mg} /$ day for 30 years for Hansen's disease without her family ever knowing. After the surgery, methemoglobin in the blood went from $8.5 \%$ to $11.0 \%$, but was untreated. From postoperative day 3 , it was treated under the diagnosis of adrenal apoplexy due to hypotension. She was discharged without complications on postoperative day 30 .

\section{Discussion}

Methemoglobin forms when hemoglobin's Fe ion oxides from ferrous $\left(\mathrm{Fe}^{2+}\right)$ to ferric $\left(\mathrm{Fe}^{3+}\right)$. In healthy adults, a small amount of hemoglobin oxides to methemoglobin and then it is rapidly

Table 1. Serial Arterial Blood Gas Analysis

\begin{tabular}{|c|c|c|c|c|c|c|c|}
\hline & $\mathrm{pH}$ & $\begin{array}{c}\mathrm{PaCO}_{2} \\
(\mathrm{mmHg})\end{array}$ & $\begin{array}{c}\mathrm{PaO}_{2} \\
(\mathrm{mmHg})\end{array}$ & $\begin{array}{l}\mathrm{SaO}_{2} \\
(\%)\end{array}$ & $\begin{array}{l}\mathrm{SpO}_{2} \\
(\%)\end{array}$ & $\begin{array}{c}\text { metHb } \\
(\%)\end{array}$ & $\begin{array}{c}\mathrm{O}_{2} \mathrm{Hb} \\
(\%)\end{array}$ \\
\hline $\begin{array}{c}\text { Before induction } \\
\text { (mask } 6 \mathrm{~L} / \mathrm{min} \text { ) }\end{array}$ & 7.547 & 33.2 & 307 & 100 & 85 & & \\
\hline $\begin{array}{l}\text { After intubation } \\
\left(\mathrm{FiO}_{2} 1.0\right)\end{array}$ & 7.503 & 31.7 & 224.7 & 96.6 & $83-85$ & 18.3 & 81.5 \\
\hline $\begin{array}{l}\text { After AA administration } \\
\left(\mathrm{FiO}_{2} 1.0\right)\end{array}$ & 7.357 & 33.3 & 387.1 & 98.6 & $85-86$ & 11.2 & 86.5 \\
\hline $\begin{array}{l}\text { After } \mathrm{MB} \text { administration } \\
\left(\mathrm{FiO}_{2} 0.5\right)\end{array}$ & 7.349 & 33.6 & 108.4 & 97.8 & $92-93$ & 4.3 & 92.8 \\
\hline $\begin{array}{r}\text { After extubation } \\
\text { (mask } 6 \mathrm{~L} / \mathrm{min})\end{array}$ & 7.375 & 38.1 & 136.1 & 96.4 & 94 & 2.3 & 93.8 \\
\hline POD 1 day & 7.388 & 35.3 & 116.2 & 100.0 & $90-92$ & 8.6 & 89.1 \\
\hline
\end{tabular}

AA: ascorbic acid, $\mathrm{MB}$ : methylene blue, $\mathrm{SaO}_{2}$ : oxygen saturation by $\mathrm{ABGA}, \mathrm{SpO}_{2}$ : oxygen saturation by pulse oximeter, metHb: methemoglobin, $\mathrm{O}_{2} \mathrm{Hb}$ : oxyhemoglobin, $\mathrm{FiO}_{2}$ : inspired oxygen fraction. 
converted back to hemoglobin such that methemoglobin levels remain below $1 \%$. This balance is maintained by the intracellular enzyme systems, NADH cytochrome- $b_{5}$ methemoglobin reductase and NADPH methemoglobin reductase [1]. Methemoglobin cannot reversibly bind with oxygen or carbon monoxide because of its additional cation, so it reduces the oxygen-carrying capacity in arterial blood. It also causes a leftward shift of the oxygen dissociation curve, increasing the affinity of the hemoglobin for oxygen and reducing tissue oxygen supply.

Symptoms of methemoglobinemia are primarily related to the level of methemoglobin but are also influenced by other factors, such as the total hemoglobin level and the cardiovascular status and the respiratory function. Usually, at methemoglobin levels below $15 \%$, patients have no clinical symptoms if adequate hemoglobin levels and preserved cardiac output is sufficient. However, when methemoglobin levels are $15-20 \%$, blackbrown blood and cyanosis occur. Higher levels (20-45\%) cause headaches, somnolence, tachycardia, lethargy, and dizziness. When it is $45 \%$ or above, respiratory difficulty, acidemia, arrhythmia, heart failure, and seizures occur. When above $70 \%$, there is a high risk of death [2].

Methemoglobinemia can be caused congenitally, by certain foods, or by other unknown causes, but usually occurs when the patient is exposed to drugs or chemical substances that disturb the conversion of methemoglobin to hemoglobin and quicken the development of methemoglobin. When discovered in the perioperative period, it is usually due to the exposure of drugs or chemical substances such as: amyl nitrite, ethyl nitrite, sodium nitrite, silver nitrate, bismuth subnitrate, nitroglycerin, quinones, sulfonamide, sulfapyridine, sulfathiazole, aniline dye, acetanilid, aminobenzenes, aminophenol, benzocaine, prilocaine, and phenacetin [3]. The drugs used in anesthetic practice that cause methemoglobinemia are prilocaine, benzocaine, amyl nitrite, nitroglycerine, phenacetin, and sulfonamide. Drug exposure and subsequent perioperative hypoxia may therefore indicate methemoglobinemia.

Dapsone is a sulfone antibiotic used for the treatment of Hansen's disease and other dermatologic diseases, as well as in immunosuppressed patients to prevent pneumocystitis carinii pneumonia or organ transplant patients, especially those intolerant to sulfonamide. Methemoglobinemia is a known side-effect of dapsone [4-6] and the patients of most cases had a history of dapsone-intake. The patient here had a 30 -year history of dapsone-intake, although this information was not obtained initially. Dapsone is almost completely absorbed in the gastrointestinal track and passes the enterohepatic circulation. Only $20 \%$ of the dosage-intake is excreted into the urine. The plasma half-life varies from 10 to 80 hours and is dose-dependent.
The pulse oximeter uses 2 wavelengths, $660 \mathrm{~nm}$ and $990 \mathrm{~nm}$, to calculate oxygen saturation because the absorbance difference between oxyhemoglobin and deoxyhemoglobin is maximized. Methemoglobin has the same absorbability as oxyhemoglobin and deoxygemoglobin so can affect oxygen saturation measurements by pulse oximeter [7]. Low methemoglobin levels slight decrease oxygen saturation measurements to a limit of $85 \%$, even with fatal methemoglobin levels. Therefore, the pulse oximeter cannot monitor methemoglobin levels. Arterial blood gas analysis calculates oxygen saturation based on arterial oxygen tension and the temperature and may not reflect actual oxygen saturation. Methemoglobinemia diagnosis includes cyanosis; low arterial oxygen saturation that cannot be explained by a problem in the respiratory system or cardiovascular system; and when the normal oxygen partial pressure in the arterial blood gas analysis does not align with the oxygen saturation by the pulse oximeter. Oxygen carrying status is most accurately measured by analysis of all hemoglobin types with a CO-oximeter [7]. Methemoglobinemia may cause blackish brown blood to remain so after exposure to air. Congenital, chronic methemoglobinemia involves a family history or exposure to drugs and toxins, which could be captured in an accurate history. Here, before anesthesia the patient showed cyanosis and low oxygen saturation on the pulse oximeter, which did not align with the arterial blood gas analysis. However, the diagnosis of dyshemoglobins was delayed because of the patient refusal to share her medical history.

Methemoglobin levels were $18.3 \%$ initially, and the patient had asymptomatic cyanosis and was hemodynamically stable, but she was given immediate treatment. Despite adequate manual ventilation with oxygen at $6 \mathrm{~L} / \mathrm{min}$ during anesthetic induction, the patient developed worsened cyanosis and showed decreased oxygen saturation by pulse oximeter to $79 \%$. The eldely patient had diabetes, hypertension, and anemia, potentially indicating ischemic heart disease or impairment in the oxygen-carrying capacity. Ascorbic acid and methylene blue treatment reduced methemoglobin levels to $11.2 \%, 4.3 \%$, followed by maintenance of hemoglobin level with $2 \mathrm{U}$ of packed red cells.

Cyanosis and $85 \%$ oxygen saturation on pulse oximeter before anesthesia could indicate high methemoglobin levels. Despite adequate preoxygenation and manual ventilation with oxygen at $6 \mathrm{~L} / \mathrm{min}$ anesthesia reduced oxygen saturation by pulse oximeter to $79 \%$ and the cyanosis worsened. The anesthetics propofol, vecuronium, and enflurane are not oxidants that develop methemoglobin, although local anesthetics like prilocaine and benzocaine do, and it is uncertain that lidocaine is a oxidant [8]. After tracheal intubation and manual ventilation with oxygen at $6 \mathrm{~L} / \mathrm{min}$, the pulse oximeter went up to $84-85 \%$ 
and cyanosis decreased. Therefore, reduced oxygen saturation during anesthetic induction resulted from normal respiratory depression and not anesthetic drugs [8]. In healthy patients, the slight respiratory depression and reduced arterial oxygen partial pressure caused respiratory depressants may be ignored, but in methemoglobinemia, they may cause seriously low oxygen saturation.

Methemoglobinemia treatment is immediate intravenous administration of methylene blue $(1-2 \mathrm{mg} / \mathrm{kg})$ and the removal of toxins or drugs that could cause it. Methylene blue acts as a cofactor of methemoglobin reductase and accelerates the enzymatic breakdown of methemoglobin. Methylene blue may be readministered every 30-60 minutes [9]. Higher levels (4-15 $\mathrm{mg} / \mathrm{kg} /$ day) can directly oxidize hemoglobin to methemoglobin and cause hemolytic anemia in glucose-6-phosphate dehydrogenase deficient patients. Methemoglobin levels above 30\% should be treated, but methemoglobin levels below $15 \%$ may seem clinically insignificant. However even when the methemoglobin level is low, treatment is recommended for patients with symptoms or underlying diseases with decreased oxygencarrying capacity such cardiac disease, pulmonary disease, carbon monoxide intoxication, anemia, or acidosis [10]. Lifethreatening methemoglobinemia unresponsive to methylene blue may occasionally respond to ascorbic acid as well, although ascorbic acid works slowly. Other reported treatments are homogeneous transfusion, exchange transfusion, and hyperbaric oxygen treatment.

In conclusion, methemoglobinemia is rare, but can be caused by drugs or chemical substances. The anesthesiologist should perform pulse oximeter and arterial blood gas analysis on patients with cyanosis. When the two results do not align, or when the oxygen saturation by pulse oximeter does not align with the clinical manifestations, methemoglobinemia should be suspected. The presence of dyshemoglobin should be confirmed by performing a hemoglobin analysis with a CO-oximeter. Methemoglobinemia should be treated with methylene blue when necessary according to methemoglobin level, symptom, and underlying diseases.

\section{References}

1. Jaffé ER. Methaemoglobinaemia. Clin Haematol 1981; 10: 99-122.

2. Curry S. Methemoglobinemia. Ann Emerg Med 1982; 11: 214-21.

3. Wright RO, Lewander WJ, Woolf AD. Methemoglobinemia: etiology, pharmacology, and clinical management. Ann Emerg Med 1999; 34: 646-56.

4. Mayo W, Leighton K, Robertson B, Ruedy J. Intraoperative cyanosis: a case of dapsone-induced methaemoglobinaemia. Can J Anaesth 1987; 34: 79-82.

5. Talarico JF, Metro DG. Presentation of dapsone-induced methemoglobinemia in a patient status post small bowel transplant. J Clin Anesth 2005; 17: 568-70.

6. Yang JJ, Lin N, Lv R, Sun J, Zhao F, Zhang J, et al. Methemoglobinemia misdiagnosed as ruptured ectopic pregnancy. Acta Anaesthesiol Scand 2005; 49: 586-8.

7. Haymond S, Cariappa R, Eby CS, Scott MG. Laboratory assessment of oxygenation in methemoglobinemia. Clin Chem 2005; 51: 43444.

8. Baraka AS, Ayoub CM, Kaddoum RN, Maalouli JM, Chehab IR, Hadi UM. Severe oxyhemoglobin desaturation during induction of anesthesia in a patient with congenital methemoglobinemia. Anesthesiology 2001; 95: 1296-7.

9. Khan NA, Kruse JA. Methemoglobinemia induced by topical anesthesia: a case report and review. Am J Med Sci 1999; 318: 415-8.

10. Harvey JW, Keitt AS. Studies of the efficacy and potential hazards of methylene blue therapy in aniline-induced methaemoglobinaemia. Br J Haematol 1983; 54: 29-41. 